https://doi.org/10.37208/tgn27325

\section{On the Wildside 2: what the Glasgow Botanic Gardens Wildside project has achieved and what remains to be done}

\author{
R.B. Weddle ${ }^{1}$ and J.R. Downie ${ }^{2}$ \\ ${ }^{1} 89$ Novar Drive, Glasgow G12 9SS \\ ${ }^{2}$ School of Life Sciences, Graham Kerr Building, \\ University of Glasgow, Glasgow G12 8QQ \\ ${ }^{1}$ E-mail: richard@ canto.plus.com
}

When Downie \& Forster (2019) introduced the five papers constituting the first part of the On the Wildside Revisited supplement, the context was twofold. First, the work was a follow-up to biodiversity surveys carried out in the late 1990s, about two decades ago. Second, the new surveys were a contribution to the celebratory events associated with the bicentenary in 2017 of the Glasgow Botanic Gardens, Scotland. Introducing this second set of papers (two full papers and six short notes) presents a good opportunity to reflect on what the whole process has achieved and what still needs to be done.

We should define the area covered by the surveys. This was not done for the original On the Wildside supplement, published in two parts in separate issues of The Glasgow Naturalist (Hancock, 1998, 1999). However, close reading of Macpherson (1998) on the plants shows that recording extended some way beyond the Gardens' gates into the area along the River Kelvin. The map (Fig. 1) shows the Gardens, the river and the vegetated river-sides from the Garrioch Flint Mill on the southeast to the disused railway bridge adjacent to Kelvinside Allotments. The biological records we report on come primarily from the Gardens sensu stricto but do extend into this riverine area. Fig. 1 includes dots showing the distribution of records.

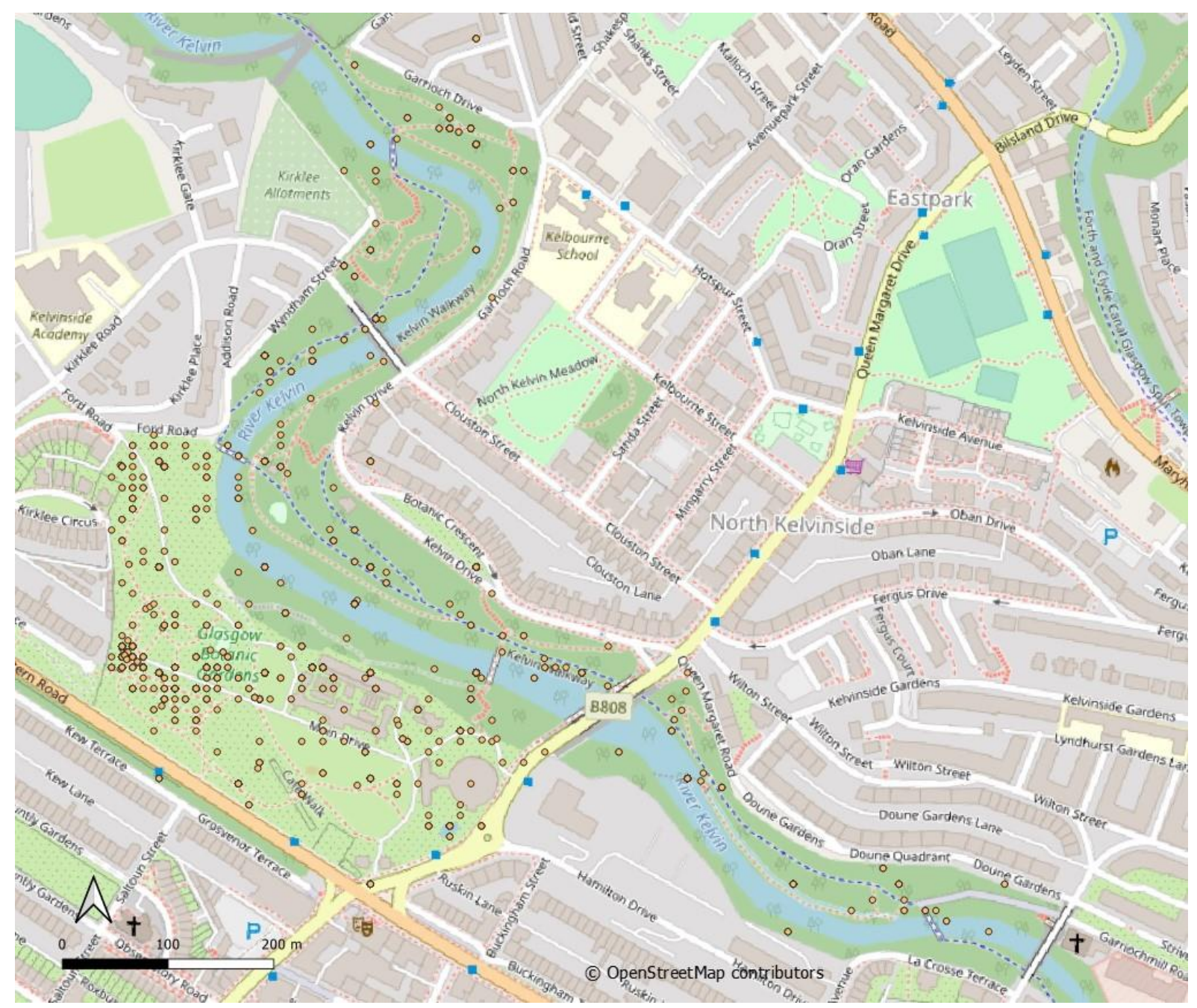

Fig. 1. Map of Glasgow Botanic Gardens, Scotland and surrounding area. The dots show the distribution of records; those falling in the surrounding urban area represent records with rather wayward National Grid References. 
What species are included? Glasgow Botanic Gardens hold a large variety of plant species and varieties brought from around the world, both under cover and in the open, depending on their hardiness to Scottish weather. The intention of the Wildside project has been to record the plants and animals living in the wild state in this area, rather than the specially cultivated species. However, cultivated species can reproduce and spread, and Macpherson (1998) listed both native wild plants and aliens, many of them species that are cultivated in the Gardens but which had escaped beyond their original sites. Gray's paper (1998) on the trees went further, listing and measuring not only wild trees beyond the Gardens' gates but also the trees planted as part of the Gardens' collections.

What of the animals? When we describe an animal species as being present in the Gardens, or observed there, what does that imply? In the case of migratory birds, they may simply be flying over: should they be included in the species lists? Such birds are noted in this issue (McInerny, 2021), but are only included in the database of records when they have been observed on the ground, or on vegetation, or on water in the project area. And what of domestic animals? The mammal species list (Sutcliffe, 2019) includes domestic dogs and cats (a feral one), and even a likely pet rabbit (earlier records may have been of wild ones), but we have excluded these from the records database on grounds of consistency. Similarly, the goldfish and tropical freshwater fish in ponds in the glasshouses are not included in the database.

And what of the organisms that are neither plants nor animals? On the basis of Whittaker's Five Kingdom system (Whittaker, 1969), biologists recognise five major groups of organisms: plants, animals, fungi, protists (single-celled organisms with nuclei) and prokaryotes (single-celled organisms lacking nuclei, such as bacteria). As we shall see, some natural historians have an enthusiastic interest in fungi, and they are well recorded. However, protists and prokaryotes are groups needing more specialised expertise, and have been much less recorded.

The complete records list for the Gardens (January 2021; www.gnhs.org.uk/biodiversity/GBG_splist.pdf) shows 1,384 species and 4,454 records, some species having been recorded more than once. The list also shows the year of first and most recent recording, and the number of times each species has been recorded (this is distinct from the relative abundance of the species, as each record could be of multiple individuals). Fig. 2 sorts the records into time periods. Records began long before the Wildside project, but were sparse in the 19th century ( 73 records) and accelerated only in the 21 st century, $78 \%$ of records having been made since the year 2000 . This pattern clearly has little to do with the arrival of new species into the area, though there has been some of that, but more to do with an increasing interest in recording urban biodiversity, and the expertise and enthusiasm of particular recorders. A nice expression of the difficulties in increasing our records of some species

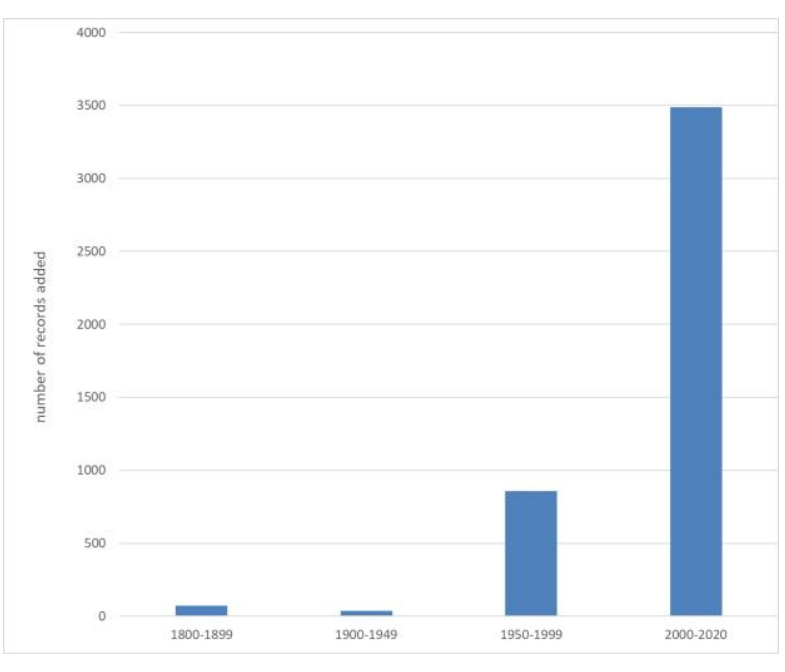

Fig. 2. The number of records of organisms in Glasgow Botanic Gardens generated over the centuries.

comes from the referee of the short note on a small leafhopper (Weddle, 2021): "I fear that the scarcity of records... in Scotland and northern England is a reflection of several factors: the scarcity of entomologists in those regions, especially ones who regularly look at this particular group of insects, and perhaps a reluctance to dissect small pale species such as this species that look very similar externally and differ on the basis of rather minor internal features."

Fig. 3 and Fig. 4 sort the species into 16 separate groups, the two largest being vascular plants (over 400) and moths (230). Group and species accounts amongst the 13 papers and short notes published in the Wildside Revisited series to date (2019 and 2021) comment on notable recent additions and apparent losses. Overall, it is only possible to make such comments on organism groups that are surveyed frequently and where we have relevant expertise.

We feel that it is worthwhile here to draw attention to the major gaps, hoping that they may be filled in future. Protists are heavily under-recorded, with single records only for protozoa and slime moulds. Both groups require expertise, but could be rewarding: an online account (Featherstone, 2012) of slime moulds in a single Scottish forest reports over 70 species. Prokaryotes require even more specialised knowledge, but many cause diseases of plants and it should be possible to record some of them. Freshwater habitats in the study area have been little sampled for records, although adult insects emerging from aquatic larvae feature strongly in the database (for example, 31 caddis flies; three dragonflies or damselflies; nine mayflies; but no stoneflies). The records we do have rely heavily on the moth traps which also capture other flying insects. In the glasshouse ponds, the invasive tropical snail Melanoides tuberculatus is recorded, since it was not introduced deliberately. However, there may be other freshwater invertebrates in the ponds, so far unnoticed. 


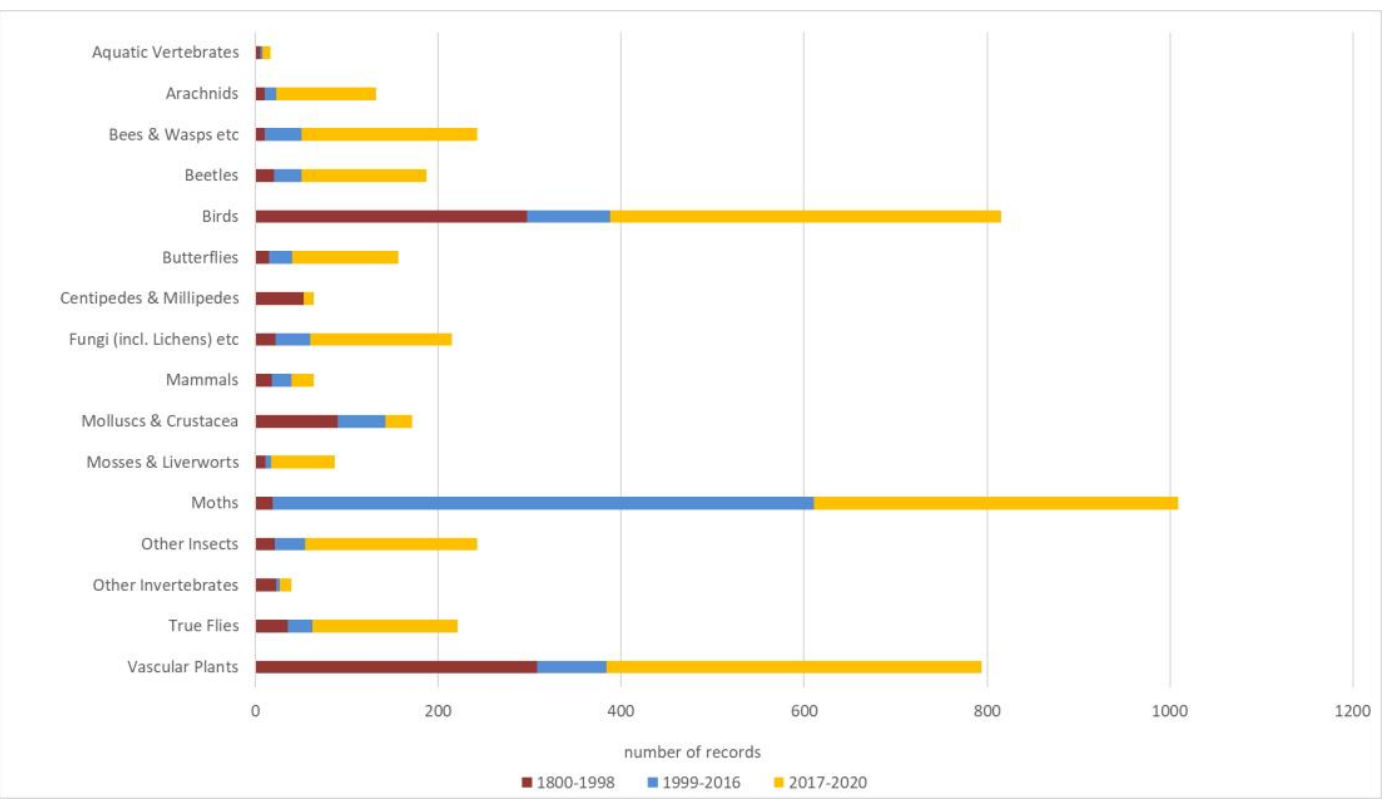

Fig. 3. The number of records for each organismal group in Glasgow Botanic Gardens before the 1999 Wildside reports, between then and the bicentenary of the Gardens in 2017, and during the Wildside Revisited project to date.

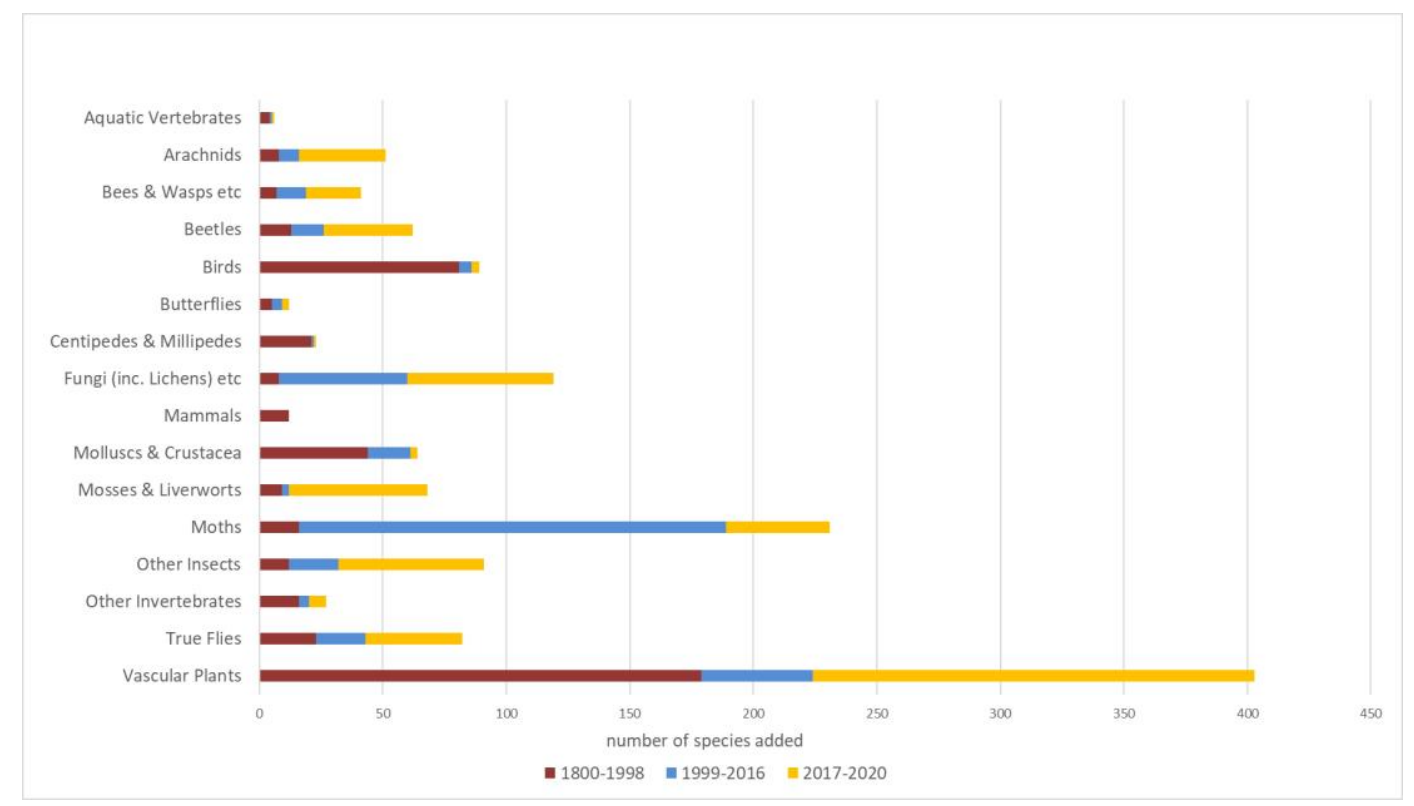

Fig. 4. The number of species within each organismal group in Glasgow Botanic Gardens first recorded before the 1999 Wildside reports, between then and the bicentenary of the Gardens in 2017, and during the Wildside Revisited project to date.

Downie \& Forster (2019) expected that the second batch of Wildside Revisited papers would be published in 2020, but this was not to be. Even the current set is not the end. We expect papers on mosses and liverworts, vascular plants, and arachnids to appear in due course, and on other topics once worthwhile new observations are made and some existing specimens have been identified. The preparation of good quality papers cannot be rushed, especially when the contributors are volunteers.

We hope that readers will feel that these contributions are worth the wait, and that the new information accumulated will not be the end of the process. The 'wildside' of the Gardens will be worth visiting repeatedly in future.

\section{REFERENCES}

Downie, J.R. \& Forster, S.J. (2019). On the Wildside 2: the natural history of the Glasgow Botanic Gardens revisited. The Glasgow Naturalist 27(1), 49. https://doi.org/10.37208/tgn27108

Featherstone, A.W. (2012). In search of slime moulds. https://alanwatsonfeatherstone.com/in-search-ofslime-moulds/ Accessed 26th January 2021.

Gray, R.K.S. (1998). Trees of Glasgow Botanic Gardens. The Glasgow Naturalist 23(3), 49-52.

Hancock, E.G. (Editor) (1998). On the Wildside: the natural history of the Glasgow Botanic Gardens. The Glasgow Naturalist 23(3), 40-56.

Hancock, E.G. (Editor) (1999). On the Wildside: the natural history of the Glasgow Botanic Gardens. The Glasgow Naturalist 23(4), 59-64. 
McInerny, C.J. (2021). The birds of Glasgow Botanic Gardens. The Glasgow Naturalist 27(3), 72-76. https://doi.org/10.37208/tgn27310

Macpherson, P. (1998). Plants growing in a wild state. The Glasgow Naturalist 23(3), 44-49.

Sutcliffe, R. (2019). Non-avian vertebrates in Glasgow Botanic Gardens. The Glasgow Naturalist 27(1), 6970.

https://doi.org/10.37208/tgn27113

Weddle, R.B. (2021). Edwardsiana alnicola (Hemiptera: Cicadellidae): a leaf-hopper new to Scotland, in Glasgow Botanic Gardens. The Glasgow Naturalist 27(3), 92.

https://doi.org/10.37208/tgn27317

Whittaker, R.H. (1969). New concepts of kingdoms of organisms. Science 163, 150-159.

https://doi.org/10.1126/science.163.3863.150 